\title{
Substance use in children of parents with chronic pain - the HUNT study
}

This article was published in the following Dove Press journal: Journal of Pain Research

2I August 2014

Number of times this article has been viewed

\author{
Jannike KaasbølI' \\ Stian Lydersen' \\ Marit S Indredavik ${ }^{1,2}$ \\ 'Regional Centre for Child and Youth \\ Mental Health and Child Welfare of \\ Central Norway, Faculty of Medicine, \\ Norwegian University of Science \\ and Technology, Trondheim, Norway; \\ ${ }^{2}$ Department of Child and Adolescent \\ Psychiatry, St Olav's Hospital, \\ Trondheim University Hospital \\ Trondheim, Norway
}

Purpose: The aim of the present study was to investigate possible associations between parental chronic pain and smoking, alcohol, and drug use in adolescent offspring.

Methods: Cross-sectional data from Nord-Trøndelag Health Study (HUNT 3), a Norwegian population-based health survey conducted in the period 2006-2008 was utilized. The present sample consisted of adolescents aged $13-18$ years $(n=3,227)$ for whom information was available on maternal and paternal health statuses.

Results: Results from multivariable ordinal and binary logistic regression analyses, adjusting for potential confounding factors (child age, parental age, education, and organ specific illness) indicated that the estimated odds ratios (OR) for smoking (OR $=1.72,95 \%$ confidence interval [CI] $[1.00,3.05], P=0.049)$ and alcohol intoxication (drunkenness) $(\mathrm{OR}=1.56,95 \% \mathrm{CI}[1.05,2.33]$, $P=0.029)$ were higher for boys whose mother and father had chronic pain, compared with boys for whom neither parent had chronic pain. These associations were slightly attenuated by additional adjustment for pain-related factors, such as parental smoking and symptoms of anxiety and depression. Parental chronic pain was not significantly associated with girls' levels of substance use. There were significant interaction effects between parental chronic pain and child sex on offspring's alcohol intoxication and smoking.

Conclusion: The present study expands on existing knowledge and provides groundwork for preventive and specific measures targeting substance use in families burdened with parental chronic pain.

Keywords: adolescents, chronic pain, smoking, alcohol, drugs

\section{Introduction}

Chronic pain is a major health care problem in industrialized countries, ${ }^{1}$ and $19 \%$ of adult Europeans report chronic pain of moderate to severe intensity. ${ }^{2}$ The condition incurs substantial personal, economic, and social costs for family members. ${ }^{3}$ An increasing body of research literature and clinical reports has suggested that the whole family, including the offspring, could potentially be affected by the strain caused by chronic pain. According to recent studies, parental chronic pain is associated with children's physical health ${ }^{4-7}$ and psychological adjustment. ${ }^{8,9}$ Knowledge about the health-related factors in the family context of chronic pain sufferers is important, as the family environment is central in the treatment of chronic pain. ${ }^{10}$ The way the family copes with these difficulties argues for examining chronic pain in the context of the chronic pain sufferers' primary social network: the family, including the children. ${ }^{11}$ However, to our knowledge, no studies have investigated potential health risk behavior, such as substance use, in the offspring of parents with chronic pain.
Correspondence: Jannike Kaasbøll Regional Centre for Child and Youth Mental Health and Child Welfare of Central Norway, Faculty of Medicine, Norwegian University of Science and Technology, Postbox 8905, Medisinsk teknisk forskningssenter, N-749I

Trondheim, Norway

Tel +4795 191 984

Fax +47 73551539

Email jannike.kaasboll@ntnu.no 
Several perspectives and findings from previous studies could explain a potential link between parental chronic pain and substance use in the offspring. First, children could learn health risk behaviors from parental role models. ${ }^{12}$ Smoking cigarettes and substance use is prevalent among individuals with chronic pain. ${ }^{13,14}$ Furthermore, chronic pain is related to increased frequency of psychiatric disorders, and also divorce or dissolved families, factors that in turn are associated with increased levels of substance use. ${ }^{15-17}$ It is well established that children whose parents are substance users are at increased risk of problems with substance use themselves. ${ }^{18,19} \mathrm{~A}$ recent literature review on children of parental chronic non-cancer pain ${ }^{20}$ points out that future studies should uncover variables that influence the associations between parental pain and child outcomes.

The potential risk of substance use in children of parents with chronic pain may also be influenced by heredity and gene-environment interactions $\mathrm{s}^{21-24}$ and both maternal and paternal factors could contribute to genetic and environmental influence on the offspring. Some of the previous studies on children of parents with chronic pain are limited by only including one parent. ${ }^{25,26}$ Furthermore, recent studies indicate an additive effect of parental chronic pain on children's psychological and physical health. ${ }^{5,8}$ That is, the effects of having both parents with chronic pain are greater than having one or neither parents with chronic pain. Hence, research on this topic should include independent information from the offspring's mother and father.

Parental chronic pain has been associated with increased levels of internalizing symptoms in offspring ${ }^{8,9}$ which in turn are linked to adolescent substance use. ${ }^{27,28}$ Symptoms of anxiety and depression were associated with high numbers of alcohol intoxications among adolescent girls in a Norwegian population based study. ${ }^{29}$ Boys with symptoms of anxiety or depression have been found to demonstrate higher risk for initiation of drug habits. ${ }^{30}$ Generally, boys tend to engage more frequently than girls in a number of adverse health-related risk behaviors, including substance use..$^{31,32}$ However, the frequency of smoking, drinking alcohol, and using drugs tends to equalize among adolescent girls and boys with increasing age. ${ }^{29,33}$ Hence, the associations between parental chronic pain and substance use in children might be influenced by the offspring's sex and age.

Contextual factors that increase the level of chronic pain in parents, such as older age and lower levels of education, ${ }^{34}$ could also be associated with substance use in the offspring, ${ }^{29,35}$ and could therefore be considered as confounding factors. Other associated conditions in chronic pain sufferers, such as increased levels of smoking and mental distress, may add to the burden for the children. Taken together, these perspectives and research findings suggest that parental chronic pain and the comorbid conditions of parental chronic pain, as well as child factors, may influence the trajectories of risk for substance use in the offspring.

In the present study, our objective was to investigate the associations between parental chronic pain, smoking, alcohol intoxication (drunkenness), and drug use in the adolescent offspring. We aimed to examine the unique contribution of maternal and paternal chronic pain, in addition to concurrent maternal and paternal chronic pain. ${ }^{29}$

\section{Material and methods Study design and procedures}

The current study was based on data from a large populationbased survey of central Norway: the Nord-Trøndelag Health Study (HUNT 3). ${ }^{36}$ All inhabitants aged 13 years and older were invited to take part in the survey during 2006-2008. In the adolescent part (Young-HUNT 3), ${ }^{37}$ participants aged 13 to 19 years old were included. The participants completed a comprehensive self-administered questionnaire on health and lifestyle. Data from HUNT 3 and Young-HUNT 3 were merged through the Norwegian family register, using the 11-digit personal number by which every citizen in Norway is registered. The design was cross-sectional.

\section{Participants}

In the Young-HUNT 3 survey, 8,200 adolescents participated ( $78 \%$ of those invited). In the adult HUNT 3 survey, 50,839 persons $\geq 20$ years old participated (attendance rate $54 \%$ ). The present sample consisted of adolescents in Young-HUNT 3 who had both parents participating in the adult HUNT study $(\mathrm{n}=3,436)$. Participants who were 12 years old $(n=19), 19$ years old $(n=157)$, and 20 years old $(n=33)$ were excluded from the analysis due to low attendance. Thus, the sample consisted of 3,227 adolescent participants of whom 608 (20\%) had mothers with chronic pain (M-group), 495 (16\%) had fathers with chronic pain (F-group), 230 (7\%) had both parents who reported chronic pain (MF-group), and 1,740 (57\%) adolescents had parents without chronic pain (reference group). In addition, 154 adolescents had missing data on parental chronic pain items. For girls $(n=1,594)$, the mean age (standard deviation [SD]) was 15.7 (1.67) years and for boys $(n=1,633)$, the mean age (SD) was 15.8 years (1.62). The number of 
boys and girls in the different groups according to parental chronic pain is presented in Tables 1 and 2, respectively. A more detailed description of the sample is provided in Kaasbøll et al. ${ }^{8}$

\section{Measures}

\section{Exposure variables: parental chronic pain}

Two questions were combined as a single measure of parental chronic pain: "Do you have physical pain now that has lasted more than 6 months?" (Yes/No) and "How strong has your physical pain been during the last four weeks?" This verbal pain rating scale included six response categories ranging from no pain (0) to very strong pain (5). The verbal rating scale is a commonly used pain rating scale recommended as a global measurement of pain severity. ${ }^{38} \mathrm{~A}$ cut-off point at the midpoint of the scale (no to mild versus moderate to very severe pain) has been shown to be useful in identifying persons with clinically significant pain. ${ }^{39}$ The combination of reporting pain lasting more than 6 months and moderate/ severe/very severe pain during the past month made the case for ascertainment of parental chronic pain.

\section{Outcome variables: adolescent smoking, alcohol intoxication, and drug use}

To assess smoking, the adolescents were asked, "Have you ever tried smoking?" (Yes/No). If the response was positive, they were asked, "Do you smoke now?" The response alternatives were: 1) "Yes, I smoke daily"; 2) "Yes, I smoke occasionally, but not daily"; 3) "No, but earlier I smoked occasionally"; 4) "No, but earlier I smoked daily"; and 5) "No, I don't smoke." In the present study, we defined a three category ordinal smoking variable as follows: Daily smoking was defined as "Yes, I smoke daily". Occasional smoking as "Yes, I smoke occasionally but not daily". Adolescents who previously had smoked or who had never smoked cigarettes were classified as non-smokers. Alcohol intoxication (drunkenness) was assessed by the question: "Have you ever drunk so much alcohol that you felt intoxicated (drunk)?" The response categories were given on a six-point ordinal scale (No, never/Yes, once/Yes, 2-3 times/ Yes, 4-10 times/Yes, 11-25 times/Yes, more than 25 times). This measurement is known to be easy to collect, fairly stable, and easily remembered by youths. ${ }^{40}$ Drug use was assessed by the question "Have you ever tried hash, marijuana, or other drugs?" The response scale was dichotomous "Yes/No".

\section{Potential confounding factors}

Socio-economic status was measured by the highest attained level of education for parents, obtained from the National Education Database. Data from 2008 were used for the current analyses. Educational attainments were re-classified into three levels: compulsory education ( $<10$ years), upper secondary education (10-12 years), and higher-level (tertiary) education ( $\geq 13$ years). Organ-specific diseases included self-report of

Table I Prevalence of adolescent boys self-reported smoking, alcohol intoxication, and drug use by parental chronic pain status

\begin{tabular}{|c|c|c|c|c|c|c|c|c|}
\hline & \multicolumn{8}{|c|}{ Chronic pain } \\
\hline & \multicolumn{2}{|c|}{ Mother } & \multicolumn{2}{|c|}{ Father } & \multicolumn{2}{|c|}{ Mother and father } & \multicolumn{2}{|c|}{ Reference $^{c}$} \\
\hline & $\mathbf{n}$ & (\%) & $\mathbf{n}$ & (\%) & $\mathbf{n}$ & (\%) & $n$ & (\%) \\
\hline Boys $(n=1,633)$ & 313 & & 234 & & 124 & & 873 & \\
\hline \multicolumn{9}{|l|}{ Smoking } \\
\hline No & 275 & $(90.5)$ & 213 & $(93.4)$ & 99 & $(82.5)$ & 765 & $(91.2)$ \\
\hline Occasionally & 18 & $(5.9)$ & 9 & $(3.9)$ & 13 & $(10.8)$ & 52 & $(6.2)$ \\
\hline \multirow[t]{2}{*}{ Daily } & II & (3.6) & 6 & $(2.6)$ & 8 & $(6.7)$ & 22 & $(2.6)$ \\
\hline & 304 & $(100.0)$ & 228 & $(100.0)$ & 120 & $(100.0)$ & 839 & $(100.0)$ \\
\hline \multicolumn{9}{|l|}{ Alcohol intoxication ${ }^{\mathrm{a}}$} \\
\hline Never & 110 & $(43.3)$ & 82 & $(47.1)$ & 29 & $(29.6)$ & 322 & $(47.2)$ \\
\hline Once & 21 & $(8.3)$ & 11 & $(6.3)$ & 5 & $(5.1)$ & 44 & $(6.5)$ \\
\hline $2-3$ times & 25 & $(9.8)$ & 21 & $(12.1)$ & 12 & $(12.2)$ & 56 & $(8.2)$ \\
\hline 4-10 times & 32 & $(12.6)$ & 27 & $(15.5)$ & 14 & $(14.3)$ & 85 & $(12.5)$ \\
\hline $\mathrm{II}-25$ times & 22 & $(8.7)$ & 9 & $(5.2)$ & II & $(I I .2)$ & 59 & $(8.7)$ \\
\hline \multirow[t]{2}{*}{ More than 25 times } & 44 & $(17.3)$ & 24 & $(13.8)$ & 27 & $(27.6)$ & 116 & $(17.0)$ \\
\hline & 254 & $(100.0)$ & 174 & $(100.0)$ & 98 & $(100.0)$ & 682 & $(100.0)$ \\
\hline \multicolumn{9}{|l|}{ Drugs $^{b}$} \\
\hline No & 298 & $(96.8)$ & 224 & $(96.6)$ & 118 & $(95.9)$ & 824 & $(96.6)$ \\
\hline \multirow[t]{2}{*}{ Yes } & 10 & $(3.2)$ & 8 & $(3.4)$ & 5 & $(4.1)$ & 29 & $(3.4)$ \\
\hline & 308 & $(100.0)$ & 232 & $(100.0)$ & 123 & $(100.0)$ & 853 & $(100.0)$ \\
\hline
\end{tabular}

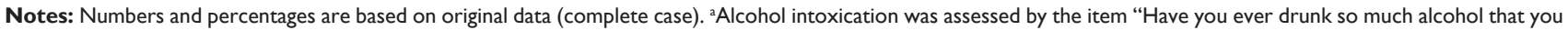
felt intoxicated (drunk)"; 'drug use was assessed by the item "Have you ever tried hash, marijuana or other drugs?"; 'neither mother or father had chronic pain. 
Table 2 Prevalence of adolescent girls self-reported smoking, alcohol intoxication, and drug use by parental chronic pain status

\begin{tabular}{|c|c|c|c|c|c|c|c|c|}
\hline & \multicolumn{8}{|c|}{ Chronic pain } \\
\hline & \multicolumn{2}{|c|}{ Mother } & \multicolumn{2}{|c|}{ Father } & \multicolumn{2}{|c|}{ Mother and father } & \multicolumn{2}{|c|}{ Reference $^{c}$} \\
\hline & $\mathbf{n}$ & (\%) & n & $(\%)$ & $n$ & (\%) & $\mathbf{n}$ & (\%) \\
\hline Girls $(n=1,594)$ & 295 & & 261 & & 106 & & 867 & \\
\hline \multicolumn{9}{|l|}{ Smoking } \\
\hline No & 258 & (89.3) & 217 & $(85.8)$ & 90 & $(88.2)$ & 762 & (89.5) \\
\hline Occasionally & 16 & $(5.5)$ & 22 & $(8.7)$ & 7 & $(6.9)$ & 56 & $(6.6)$ \\
\hline \multirow[t]{2}{*}{ Daily } & 15 & $(5.2)$ & 14 & $(5.5)$ & 5 & $(4.9)$ & 33 & $(3.9)$ \\
\hline & 289 & $(100.0)$ & 253 & $(100.0)$ & 102 & $(100.0)$ & 851 & $(100.0)$ \\
\hline \multicolumn{9}{|l|}{ Alcohol intoxication ${ }^{\mathrm{a}}$} \\
\hline Never & 90 & (37.8) & 79 & $(35.7)$ & 35 & $(36.5)$ & 343 & $(45.9)$ \\
\hline Once & 15 & $(6.3)$ & 21 & $(9.5)$ & 6 & $(6.2)$ & 47 & $(6.3)$ \\
\hline $2-3$ times & 32 & $(13.4)$ & 28 & $(12.7)$ & 13 & $(13.5)$ & 78 & $(10.4)$ \\
\hline 4-10 times & 34 & $(14.3)$ & 35 & $(15.8)$ & 10 & $(10.4)$ & 99 & $(13.2)$ \\
\hline $\mathrm{II}-25$ times & 28 & (II.8) & 22 & $(10.0)$ & 11 & (II.5) & 65 & $(8.7)$ \\
\hline \multirow[t]{2}{*}{ More than 25 times } & 39 & $(16.4)$ & 36 & $(16.3)$ & 21 & $(21.9)$ & 116 & $(15.5)$ \\
\hline & 238 & $(100.0)$ & 221 & $(100.0)$ & 96 & $(100.0)$ & 748 & $(100.0)$ \\
\hline \multicolumn{9}{|l|}{ Drugs $^{\mathrm{b}}$} \\
\hline No & 290 & (99.3) & 254 & $(98.1)$ & 101 & $(97.1)$ & 845 & $(98.3)$ \\
\hline \multirow[t]{2}{*}{ Yes } & 2 & $(0.7)$ & 5 & $(1.9)$ & 3 & $(2.9)$ & 15 & $(1.7)$ \\
\hline & 292 & $(100.0)$ & 259 & $(100.0)$ & 104 & $(100.0)$ & 860 & $(100.0)$ \\
\hline
\end{tabular}

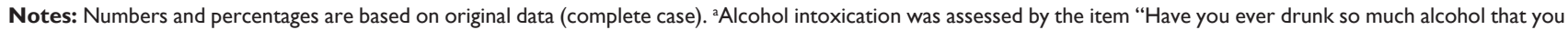
felt intoxicated (drunk)"; 'drug use was assessed by the item "Have you ever tried hash, marijuana or other drugs?"; cneither mother or father had chronic pain.

the following: myocardial infarction (heart attack), angina pectoris (chest pain), other heart disease, stroke/brain hemorrhage, kidney disease, asthma, chronic bronchitis, emphysema or chronic obstructive pulmonary disease, diabetes, cancer, and epilepsy. Responses to these questions were dichotomized into no disease or one/more diseases. Potential confounding factors also included child and parental age.

\section{Potential pain-related factors}

Parental symptoms of anxiety and depression were measured by the Hospital Anxiety and Depression Scale (HADS). ${ }^{41}$ HADS consists of seven items (4-point scale rated 0-3) concerning depression and seven concerning anxiety during the previous week. The measurement has shown good casefinding properties for anxiety and depression, as defined by the Diagnostic and Statistical Manual of Mental Disorders, Fourth Edition. ${ }^{42}$ Cronbach's $\alpha$ for maternal and paternal HADS, respectively, was 0.87 and 0.84. Parental problem drinking was identified by the CAGE (Cut-down, Annoyed, Guilty, Eye-opener) questionnaire. ${ }^{43} \mathrm{CAGE}$ consists of four dichotomous (Yes/No) questions on experiences and behavior related to the parents' use of alcohol: "Have you ever tried to cut down on your drinking?"; "Do you get annoyed when people talk about your drinking?"; "Do you feel guilty about your drinking?"; and "Have you ever had an eye-opener (a drink first thing in the morning) to steady your nerves or get rid of a hangover?" CAGE is used widely in both clinical and non-clinical settings as a screening instrument for alcohol use disorders, with good validity. ${ }^{44,45}$ For mothers, the last item was excluded to increase the Cronbach's $\alpha$ (0.59 to 0.66). The Cronbach's $\alpha$ for paternal CAGE was 0.68 . For the purposes of ordinal regression analyses, a sum-score was computed for mothers and fathers, ranging from 0 to 3 and 0 to 4 , respectively. Data on parental smoking were categorized as nonsmoker, previous smoker, or current smoker.

Adolescents' symptoms of anxiety and depression were measured by the symptom checklist-5 (SCL-5), which is based on a short version of the Hopkins Symptom Checklist SCL-25. ${ }^{46}$ The SCL-5 includes five items addressing how the subject felt for the previous 14 days, with response categories from not bothered (1) to very bothered (4). Anxiety problems included "Constantly afraid and anxious," "Felt tense or uneasy", and "Worried too much about various things". Depressive problems included "Felt hopelessness when you think of the future" and "Felt dejected or sad". This measurement has been demonstrated to be reliable in previous studies. ${ }^{46}$ Cronbach's $\alpha$ for the SCL-5 scale was 0.82 . Adolescents' cohabitation status was classified as "living with one parent" or "living with both parents", indicating a dissolved family structure if the children are living with only one parent.

\section{Statistical analyses}

All scales were constructed by using mean score indices if at least $50 \%$ of the items were available. Cronbach's $\alpha$ was used 
to test the reliability and internal consistency of the HUNT variables. Separate analyses were conducted for girls and boys. Ordinal logistic regression analysis was used to evaluate the effects of parental chronic pain on adolescent smoking and alcohol use. The odds ratio (OR) in ordinal logistic regression has the same interpretation as the OR in standard (binary) logistic regression, if a cut off were made between any two categories of the dependent variable. First, the crude OR and OR adjusted for child age were estimated. Next, we adjusted for potential confounders simultaneously: child age, parental age, education, and organ-specific illness. Finally, we performed additional adjustments to investigate whether possible intermediating factors influenced the association between parental chronic pain and offspring's substance use by adding the following variables, one at a time: adolescent cohabitation status (living with one or both parents), adolescent symptoms of anxiety and depression (SCL-5), parental psychiatric symptoms (HADS), parental problem drinking (CAGE), and parental smoking. Binary logistic regression analyses were used for drug use. Drug abuse was reported by 25 girls and 52 boys. In the analyses of drug use, we did not adjust for potential confounders or other variables in addition to age to avoid an unfavorable ratio between the number of participants and predictor variables. There ought to be at least 5 to 10 times as many cases as covariates in a logistic regression analysis, ${ }^{47,48}$ and the four chronic pain groups count as three covariates.

Multiple imputation (MI) was used to reduce bias and to avoid a loss of sample size due to missing data (levels of missing data are presented in Table S1). We imputed $\mathrm{m}=100$ data sets, as recommended by Carpenter and Kenward. ${ }^{49}$ Original data (without MI) were used to describe (cross-tabs) parental education, smoking, and organ disease (Table S1), and adolescent smoking, alcohol intoxication, and drug use (Tables 1 and 2). All regression analyses were based on MI. Analyses with and without imputed data provided similar results. To test sex differences in the association between parental chronic pain and substance use in offspring, we combined the imputed data sets for girls and boys as suggested by van Buuren, ${ }^{50}$ and included interaction terms between parental chronic pain and child sex. Where relevant, 95\% CIs are reported, and two-sided $P$-values $<0.05$ were considered significant. SPSS software, version 21.0 (IBM Corporation, Armonk, NY, USA), was used for the data analyses.

\section{Ethics}

Written consent to participate in the HUNT study was provided by all of the participants and by the parents of children under the age of 16 years old. The present study complied with the Declaration of Helsinki principles and was approved by the Regional Committee for Medical Research Ethics (reference number 4.2008.664) and by the Norwegian Social Science Data Services.

\section{Results}

The distributions of smoking, alcohol intoxication, and drug use among boys and girls according to parental chronic pain status are presented in Tables 1 and 2. Parental education, organ disease, and smoking among parents with and without chronic pain are presented in Table S1. The levels of problem drinking (CAGE) were higher in the sample of fathers with chronic pain than in the sample of fathers without chronic pain (mean difference $=0.08$ ), but the difference was not statistically significant $(95 \% \mathrm{CI}[-0.00,0.16], P=0.058)$. Further parental characteristics, such as age, symptoms of anxiety and depression (HADS), and cohabitation, as well as child symptoms of anxiety and depression (SCL-5), were described in a previous publication. ${ }^{8}$

\section{Associations between parental chronic pain and boys' substance use}

As presented in Table 3, the OR for smoking was not significantly higher for boys in the M-group or the F-group, however the OR for smoking was substantially higher in the MF-group, in crude, age-adjusted and fully-adjusted analyses, compared with boys in the reference group. For boys in the MF-group, the adjustment for pain-related factors, especially parental smoking and parental symptoms of anxiety and depression (HADS), attenuated the OR to a non-significant level. Maternal smoking, paternal smoking, and child symptoms of anxiety and depression (SCL-5) were significantly associated with adolescent smoking $(P<0.001)$. These variables changed the $\beta$-estimate for chronic pain by $-21 \%,-11 \%$, and $-4 \%$, respectively.

The crude OR for alcohol intoxication was also significantly higher in the MF-group compared with the reference group. The OR was not significantly higher in the M-group or the F-group compared with the reference group. The OR remained significant and essentially unchanged when adjusting for potential confounders and pain-related factors, including cohabitation status, child SCL-5, and parental CAGE (Table 3). Adjusting for maternal HADS and paternal smoking, the OR was reduced somewhat and to a non-significant level. Maternal smoking attenuated the OR substantially and to a non-significant level. The chronic pain $\beta$ estimate decreased by about $29 \%$ after adjustment for maternal smoking, $-16 \%$ after adjustment for paternal smoking, $-6 \%$ after adjustment for paternal problematic 
Table 3 Boys' risk of substance use if one or both parents had chronic pain, compared with reference group (no parental chronic pain)

\begin{tabular}{|c|c|c|c|c|c|c|c|}
\hline & \multirow[t]{3}{*}{$\mathbf{n}$} & \multicolumn{2}{|c|}{$\begin{array}{l}\text { Boys of mothers } \\
\text { with chronic pain } \\
n=3 \text { I } 3\end{array}$} & \multicolumn{2}{|c|}{$\begin{array}{l}\text { Boys of fathers } \\
\text { with chronic pain } \\
n=234\end{array}$} & \multirow{2}{*}{\multicolumn{2}{|c|}{$\begin{array}{l}\text { Boys of mothers and } \\
\text { fathers who both have } \\
\text { chronic pain } \\
n=124\end{array}$}} \\
\hline & & \multirow[t]{2}{*}{ OR $95 \% \mathrm{Cl}$} & \multirow[t]{2}{*}{$P$} & \multirow[t]{2}{*}{ OR $95 \% \mathrm{Cl}$} & \multirow[t]{2}{*}{$P$} & & \\
\hline & & & & & & OR $95 \% \mathrm{CI}$ & $P$ \\
\hline Smoking & $1,633^{\mathrm{a}}$ & & & & & & \\
\hline Unadjusted & $|, 49|$ & $1.09[0.70,1.72]$ & 0.895 & $0.73[0.4 \mathrm{I}, \mathrm{I} .28]$ & 0.271 & $2.21[1.31,3.72]$ & 0.003 \\
\hline Adjusted for child age & I,49! & $1.06[0.67,1.68]$ & 0.808 & $0.79[0.44, \mathrm{I} .40]$ & 0.397 & $2.09[1.22,3.57]$ & 0.007 \\
\hline Adjusted for potential confounders ${ }^{b}$ & I,446 & $0.98[0.6 \mathrm{I}, \mathrm{I} .56]$ & 0.916 & $0.75[0.42,1.35]$ & 0.343 & $1.72[1.00,3.05]$ & 0.049 \\
\hline \multicolumn{8}{|l|}{ Additional adjustments ${ }^{c}$} \\
\hline Living with one/both parents & I,375 & $0.96[0.60,1.54]$ & 0.879 & $0.75[0.42,1.35]$ & 0.337 & I.7I $[0.98,2.98]$ & 0.057 \\
\hline Child SCL-5 $5^{d}$ & 1,406 & $\mathrm{I} .01[0.63,1.61]$ & 0.971 & $0.78[0.43,1.40]$ & 0.406 & $1.69[0.96,2.95]$ & 0.067 \\
\hline Maternal HADS $(0-42)^{\mathrm{e}}$ & 1,198 & $0.95[0.59,1.52]$ & 0.822 & $0.75[0.42,1.33]$ & 0.323 & $1.60[0.90,2.85]$ & 0.110 \\
\hline Maternal smoking & 1,315 & $0.91[0.57,1.46]$ & 0.688 & $0.71[0.39,1.27]$ & 0.243 & $1.53[0.88,2.69]$ & 0.134 \\
\hline Maternal alcohol use (CAGE) $(0-3)^{g}$ & $\mathrm{I}, 084$ & $0.97[0.6 \mathrm{I}, \mathrm{I} .55]$ & 0.908 & $0.76[0.42,1.35]$ & 0.344 & $1.71[0.98,2.98]$ & 0.057 \\
\hline Paternal HADS $(0-42)^{e}$ & 1,100 & $0.99[0.62,1.58]$ & 0.953 & $0.72[0.39,1.28]$ & 0.272 & $1.63[0.91,2.80]$ & 0.093 \\
\hline Paternal smoking & I,376 & $0.95[0.59,1.51]$ & 0.822 & $0.7 \mathrm{I}[0.40,1.28]$ & 0.254 & $1.62[0.92,2.83]$ & 0.092 \\
\hline Paternal alcohol use (CAGE) $(0-4)^{g}$ & $\mathrm{I}, 084$ & $0.98[0.6 \mathrm{I}, \mathrm{I} .56]$ & 0.920 & $0.75[0.42,1.35]$ & 0.337 & $1.69[0.97,2.95]$ & 0.064 \\
\hline Alcohol intoxication & 1,633 & & & & & & \\
\hline Unadjusted & I,544 & $1.12[0.87,1.44]$ & 0.376 & $0.91[0.69,1.22]$ & 0.537 & $1.84[1.04,3.08]$ & 0.001 \\
\hline Adjusted for child age & 1,544 & $\mathrm{I} .0 \mathrm{I}[0.77, \mathrm{I} .32]$ & 0.966 & $0.98[0.70,1.36]$ & 0.886 & $1.69[1.14,2.50]$ & 0.009 \\
\hline Adjusted for potential confounders ${ }^{b}$ & ।,497 & $0.93[0.70,1.22]$ & 0.585 & $0.93[0.67,1.30]$ & 0.664 & $1.56[1.05,2.33]$ & 0.029 \\
\hline \multicolumn{8}{|l|}{ Additional adjustments ${ }^{c}$} \\
\hline Living with one/both parents & I,42I & $0.92[0.70,1.21]$ & 0.539 & $0.93[0.67,1.30]$ & 0.669 & $1.56[1.05,2.34]$ & 0.029 \\
\hline Child SCL-5 $5^{d}$ & I,45। & $0.94[0.7 \mathrm{I}, \mathrm{I} .24]$ & 0.654 & $0.94[0.67,1.32]$ & 0.725 & $1.54[1.03,2.30]$ & 0.035 \\
\hline Maternal HADS $(0-42)^{\mathrm{e}}$ & 1,234 & $0.90[0.68,1.19]$ & 0.461 & $0.92[0.66,1.28]$ & 0.625 & $\mathrm{I} .46[0.97,2.2 \mathrm{I}]$ & 0.068 \\
\hline Maternal smoking & $|, 36|$ & $0.87[0.62,1.58]$ & 0.318 & $0.87[0.43, \mathrm{I} .38]$ & 0.424 & $1.37[0.92,2.06]$ & 0.122 \\
\hline Maternal alcohol use (CAGE) $(0-3)^{g}$ & $\mathrm{I}, 140$ & $0.93[0.71,1.23]$ & 0.606 & $0.93[0.67,1.30]$ & 0.665 & $1.57[1.05,2.34]$ & 0.027 \\
\hline Paternal HADS $(0-42)^{e}$ & 1,100 & $0.93[0.7 \mathrm{I}, \mathrm{I} .23]$ & 0.614 & $0.90[0.64,1.26]$ & 0.537 & $1.51[1.01,2.26]$ & 0.045 \\
\hline Paternal smoking & $\mathrm{I}, 368$ & $0.89[0.68,1.18]$ & 0.427 & $0.87[0.62,1.38]$ & 0.398 & $1.45[0.97,2.17]$ & 0.068 \\
\hline Paternal alcohol use (CAGE) $(0-4)^{g}$ & $\mathrm{I}, 083$ & $0.94[0.7 \mathrm{I}, \mathrm{I} .24]$ & 0.656 & $0.94[0.67,1.32]$ & 0.728 & $1.54[1.03,2.29]$ & 0.036 \\
\hline 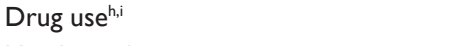 & 1,633 & & & & & & \\
\hline Unadjusted & $1,5 \mid 5$ & $\mathrm{I} .00[0.48,2.07]$ & 0.999 & $\mathrm{I} .06[0.48,2.34]$ & 0.923 & $1.19[0.45,3.14]$ & 0.723 \\
\hline Adjusted for child age & 1,515 & $0.95[0.46,1.82]$ & 0.975 & $1.18[0.53,2.62]$ & 0.693 & $\mathrm{I} .07[0.40,2.86]$ & 0.888 \\
\hline
\end{tabular}

Notes: Ordinal logistic regression (smoking and alcohol intoxication). Binary logistic regression (drug use). Reference group: boys of mothers and fathers without chronic pain ( $\mathrm{n=873).}{ }^{\mathrm{a}} \mathrm{All} \mathrm{n}$ values are reported for complete cases and the results are based on MI analyses; bchild age, parental age, education, and organ specific illness; 'adjusted for all potential confounders; da high score indicates high levels of anxiety and depression symptoms; ea high score indicates high levels of anxiety and depression symptoms; 'non/previous/current smoker; ${ }^{g}$ a high score indicates high levels of alcohol misuse; hdrug use was measured by the item "Have you ever tried hash, marijuana or other drugs" (Yes/No); 'not possible to adjust for potential confounders due to few cases in one of the response categories.

Abbreviations: CAGE, Cut-down, Annoyed, Guilty, Eye-opener questionnaire for parental problem drinking; Cl, confidence interval; HADS, Hospital Anxiety and Depression Scale; MI, multiple imputation; OR, odds ratio; SCL-5, Hopkins Symptom Checklist.

alcohol use (CAGE), and by $-3 \%$ after adjustment for adolescent symptoms of anxiety and depression (SCL-5).

The risk of increased levels of drug use was not significantly higher for boys of parents with chronic pain compared to boys in the reference group (Table 3).

\section{Associations between parental chronic pain and girls' substance use}

The crude OR of increased levels of smoking or drug use was not significantly higher for girls of parents with chronic pain compared with girls in the reference group. Adjusting for potential confounders did not change the OR substantially (Table 4).
The crude OR for alcohol intoxication was not significantly increased in the M-group (Table 4). The OR slightly increased $(P=0.034)$ when adjusting for child age, but remained essentially unchanged (non-significant) when adjusting for all confounders simultaneously. Furthermore, additional adjusting separately for painrelated factors, the OR remained essentially unchanged. In the MF-group, the crude and the age-adjusted OR for alcohol intoxication was significantly, and borderline significantly, increased, respectively. Adjusting for the confounders simultaneously slightly decreased the OR to a non-significant level, which remained essentially 
Table 4 Girls' risk of substance use if one or both parents had chronic pain, compared with reference group (no parental chronic pain)

\begin{tabular}{|c|c|c|c|c|c|c|c|}
\hline & \multirow[t]{3}{*}{$\mathbf{n}$} & \multicolumn{2}{|c|}{$\begin{array}{l}\text { Girls of mothers } \\
\text { with chronic pain } \\
n=295\end{array}$} & \multicolumn{2}{|c|}{$\begin{array}{l}\text { Girls of fathers } \\
\text { with chronic pain } \\
n=26 \text { I }\end{array}$} & \multirow{2}{*}{\multicolumn{2}{|c|}{$\begin{array}{l}\text { Girls of mothers and } \\
\text { fathers who both have } \\
\text { chronic pain } \\
n=106\end{array}$}} \\
\hline & & \multirow[t]{2}{*}{ OR 95\% Cl } & \multirow[t]{2}{*}{$P$} & \multirow[t]{2}{*}{ OR $95 \% \mathrm{Cl}$} & \multirow[t]{2}{*}{$\boldsymbol{P}$} & & \\
\hline & & & & & & OR $95 \% \mathrm{Cl}$ & $\mathbf{P}$ \\
\hline Smoking & $1,594^{a}$ & & & & & & \\
\hline Unadjusted & 1,495 & $1.05[0.68,1.61]$ & 0.642 & $1.39[0.92,2.1 \mathrm{I}]$ & 0.118 & $1.16[0.62,2.20]$ & 0.823 \\
\hline Adjusted for child age & $\mathrm{I}, 495$ & $1.07[0.69,1.65]$ & 0.770 & $1.38[0.90,2.11]$ & 0.141 & $1.08[0.56,2.08]$ & 0.813 \\
\hline Adjusted for potential confounders ${ }^{b}$ & 1,446 & $0.93[0.60,1.46]$ & 0.611 & $1.22[0.79,1.89]$ & 0.362 & $0.89[0.46,1.73]$ & 0.622 \\
\hline \multicolumn{8}{|l|}{ Additional adjustments $^{c}$} \\
\hline Living with one/both parents & $\mathrm{I}, 38 \mathrm{I}$ & $0.93[0.59,1.45]$ & 0.773 & $1.23[0.80,1.90]$ & 0.354 & $0.88[0.45,1.70]$ & 0.737 \\
\hline Child SCL-5 $5^{d}$ & 1,432 & $0.85[0.54,1.35]$ & 0.489 & $1.13[0.73,1.76]$ & 0.581 & $0.73[0.37,1.44]$ & 0.362 \\
\hline Maternal HADS $(0-42)^{\mathrm{e}}$ & $\mathrm{I}, 182$ & $0.91[0.58,1.43]$ & 0.695 & $1.22[0.79,1.88]$ & 0.371 & $0.86[0.44,1.69]$ & 0.668 \\
\hline Maternal smoking & 1,309 & $0.84[0.53,1.33]$ & 0.454 & $1.18[0.76,1.84]$ & 0.453 & $0.79[0.41,1.55]$ & 0.497 \\
\hline Maternal alcohol use (CAGE) $(0-3)^{g}$ & 1,084 & $0.94[0.60,1.47]$ & 0.773 & $1.22[0.79,1.89]$ & 0.359 & $0.90[0.46,1.74]$ & 0.749 \\
\hline Paternal HADS $(0-42)^{\mathrm{e}}$ & 1,112 & $0.95[0.60,1.49]$ & 0.822 & $\mathrm{I} .14[0.74, \mathrm{I} .77]$ & 0.555 & $0.85[0.43,1.65]$ & 0.623 \\
\hline Paternal smoking ${ }^{f}$ & $\mathrm{I}, 355$ & $1.03[0.66,1.60]$ & 0.903 & $1.26[0.82,1.94]$ & 0.282 & $0.89[0.46,1.72]$ & 0.721 \\
\hline Paternal alcohol use (CAGE) $(0-4)^{g}$ & $\mathrm{I}, 080$ & $0.93[0.60,1.46]$ & 0.767 & $1.23[0.79,1.89]$ & 0.359 & $0.88[0.46,1.74]$ & 0.738 \\
\hline Alcohol intoxication & 1,594 & & & & & & \\
\hline Unadjusted & 1,529 & $1.22[0.95,1.56]$ & 0.118 & $1.25[0.97,1.62]$ & 0.084 & $1.47[1.02,2.12]$ & 0.038 \\
\hline Adjusted for child age & 1,529 & $1.35[1.02,1.77]$ & 0.034 & $1.25[0.94,1.68]$ & 0.129 & $1.50[1.00,2.28]$ & 0.053 \\
\hline Adjusted for potential confounders ${ }^{b}$ & 1,480 & $1.27[0.96,1.68]$ & 0.090 & $\mathrm{I} .17[0.87,1.58]$ & 0.291 & $1.38[0.91,2.11]$ & 0.132 \\
\hline \multicolumn{8}{|l|}{ Additional adjustments ${ }^{c}$} \\
\hline Living with one/both parents & $\mathrm{I}, 4 \mathrm{I} 2$ & $1.27[0.96,1.67]$ & 0.098 & $1.18[0.87,1.58]$ & 0.284 & $1.38[0.90,2.10]$ & 0.138 \\
\hline Child SCL-5 $5^{d}$ & $\mathrm{I}, 463$ & $1.27[0.96,1.68]$ & 0.098 & $1.15[0.85,1.55]$ & 0.361 & $1.29[0.84,1.96]$ & 0.245 \\
\hline Maternal HADS $(0-42)^{e}$ & 1,210 & $1.26[0.94,1.65]$ & 0.121 & $1.17[0.87,1.57]$ & 0.302 & $1.35[0.88,2.06]$ & 0.168 \\
\hline Maternal smokingf & $|, 34|$ & $1.23[0.93,1.63]$ & 0.142 & $1.15[0.86,1.55]$ & 0.347 & $1.34[0.88,2.04]$ & 0.176 \\
\hline Maternal alcohol use (CAGE) $(0-3)^{g}$ & 1,104 & $1.27[0.96,1.67]$ & 0.098 & $\mathrm{I} .17[0.87,1.58]$ & 0.292 & $1.37[0.90,2.09]$ & 0.143 \\
\hline Paternal HADS $(0-42)^{\mathrm{e}}$ & 1,138 & $1.28[0.97,1.69]$ & 0.084 & $1.15[0.85,1.54]$ & 0.370 & $1.36[0.89,2.08]$ & 0.153 \\
\hline Paternal smoking & ।,355 & $1.28[0.97,1.69]$ & 0.084 & $1.16[0.86,1.56]$ & 0.335 & $1.35[0.88,2.06]$ & 0.170 \\
\hline Paternal alcohol use (CAGE) $(0-4)^{g}$ & I,078 & $1.27[0.96,1.68]$ & 0.091 & $1.16[0.86,1.56]$ & 0.328 & $1.37[0.90,2.09]$ & 0.147 \\
\hline Drug use $\mathrm{e}^{\mathrm{h}, \mathrm{i}}$ & 1,594 & & & & & & \\
\hline Unadjusted & 1,516 & $0.40[0.09,1.74]$ & 0.220 & I.II $[0.40,3.09]$ & 0.836 & $1.69[0.48,5.95]$ & 0.481 \\
\hline Adjusted for child age & 1,516 & $0.41[0.09,1.82]$ & 0.241 & $1.08[0.39,3.02]$ & 0.883 & I.53 $[0.44,5.48]$ & 0.512 \\
\hline
\end{tabular}

Notes: Ordinal logistic regression (smoking and alcohol intoxication). Binary logistic regression (drug use). Reference group: girls of mothers and fathers without chronic pain ( $n=867)$. ${ }^{a}$ All $n$ values are reported for complete cases and the results are based on Ml analyses; ${ }^{b}$ child age, parental age, education, and organ specific illness; ' adjusted for all potential confounders; da high score indicates high levels of anxiety and depression symptoms; ea high score indicates high levels of anxiety and depression symptoms; fnon/previous/current smoker; ga high score indicates high levels of alcohol misuse; 'drug use was measured by the item "Have you ever tried hash, marijuana or other drugs" (Yes/No); 'not possible to adjust for potential confounders due to few cases in one of the response categories.

Abbreviations: CAGE, Cut-down, Annoyed, Guilty, Eye-opener questionnaire for parental problem drinking; Cl, confidence interval; HADS, Hospital Anxiety and Depression Scale; MI, multiple imputation; OR, odds ratio; SCL-5, Hopkins Symptom Checklist.

unchanged when including other pain-related associated factors (Table 4).

\section{Sex differences in the association between parental chronic pain and adolescent smoking, alcohol intoxication, and drug use}

There was significant interaction between parental chronic pain and the sex of the child on both adolescent smoking $(P=0.002)$ and alcohol use $(P=0.011)$. No significant interaction was found between parental chronic pain and the sex of the child on adolescent drug use $(P=0.324)$.

\section{Discussion}

The most prominent finding in our study was that boys exposed to concurrent maternal and paternal chronic pain had a higher OR for smoking and alcohol intoxication compared with those who had neither parent with chronic pain. These associations withstood adjustments for potential confounders, but they were substantially attenuated when adjusted for pain-related factors, especially parental smoking and parental symptoms of anxiety and depression. For girls, parental chronic pain was not significantly associated with smoking, alcohol intoxication, or drug use. There were significant interaction effects of parental 
chronic pain and child sex on adolescent smoking and alcohol intoxication.

\section{Parental chronic pain and boys' substance use}

In the current study, boys who were exposed to concurrent maternal and paternal chronic pain had nearly a two-fold increased odds for smoking, even after adjusting for potential confounding factors. Our results indicated that the association between parental chronic pain and smoking in the male offspring was somewhat influenced by parental smoking and parental symptoms of anxiety and depression. However, the beta decreased by about $20 \%$ after adjustment for maternal smoking and about $10 \%$ after adjustment for paternal smoking into the analyses. This could indicate that the increased levels of smoking among boys in the MF-group may only partly be a direct modeling of parental smoking, and that parental chronic pain is still an important factor for the increased levels of smoking among boys in the MF-group. Thus, it is possible that the increased levels of smoking in parents with chronic pain contribute, both through genetic and contextual mechanisms, to the associations found in boys. Future studies, preferably longitudinal, should attempt to uncover whether parental smoking mediates the association between parental chronic pain and child substance use, especially smoking.

Adjusted for potential confounders, boys with concurrent maternal and paternal chronic pain also had a higher OR for alcohol intoxication. Although fathers with chronic pain had slightly higher levels of problematic alcohol use compared with fathers without chronic pain, our results indicate that the association between chronic pain and substance use was minimally influenced by problematic paternal alcohol use. A major predictor of adolescents' initial experimentation with substances is a lack of parental supervision and discipline. ${ }^{51}$ Parental chronic pain can, in some cases, involve withdrawing from care-giving roles ${ }^{9,52}$ and consequently lack of parental supervision regarding the use of drugs and alcohol. Therefore, we speculate that parental unavailability due to chronic pain, and not only direct modeling of behavior, plays an influential role in the boys' increased risk of alcohol intoxication. It is possible that the presence of concurrent maternal and paternal pain increases the burden in the family, and consequently affects the parenting strategies and supervision.

Adolescents' normal development and the ambivalent nature of adolescence could cause teenagers to desire autonomy, while also craving parental acceptance and support. ${ }^{52}$ During this developmental stage, some teens rebel against the authority figures in their lives. ${ }^{53}$ For some teens, this rebellion could include experimentation with drugs, smoking, or alcohol. In addition, adolescent boys who were exposed to concurrent maternal and paternal chronic pain might use alcohol and nicotine as a reaction to the potential strain that chronic pain has caused in the family. We further speculate that the normal process of separation and individuation may be more demanding in the presence of parental chronic pain, especially when both parents suffer from chronic pain.

Adolescent symptoms of anxiety and depression (SCL-5) were significantly associated with both smoking and alcohol intoxication in boys exposed to concurrent maternal and paternal chronic pain (MF-group). However, adjusting for SCL-5 only minimally influenced the association between parental chronic pain and the boys' substance use. These findings could be related to a previous study where we found that boys in the MF-group had a two-fold greater risk for internalizing symptoms. ${ }^{8}$ Internalizing disorders (depression and anxiety) and substance use often co-occur within individuals, and we cannot rule out the possibility that substance use could increase the levels of internalizing symptoms. However, as Marmorstein et $\mathrm{al}^{54}$ have pointed out, it is unlikely that the initial use of a substance directly causes changes in internalizing symptoms, and vice versa. They further speculate that the initial substance use and internalizing symptoms represent transition points in development, and could be markers for broader changes that are occurring in a variety of contexts (eg, family) in the adolescent's life. Hence, one should pay attention to potential intertwined internalizing symptoms and health risk behavior, such as substance use, among adolescents whose families are burdened with concurrent maternal and paternal chronic pain.

\section{Parental chronic pain and girls' substance use}

The results indicate that for girls, parental chronic pain was not significantly associated with substance use. We found a significant interaction between parental chronic pain and child sex on offspring's smoking and alcohol use, and this may support the notion that girls do not display the same tendency towards a heightened risk of substance use as boys who are exposed to parental pain. As a consequence of parental illness and/or disability, children may have increased family responsibilities and they may adopt a care-giving role. ${ }^{55,56}$ Furthermore, they might be at risk of inappropriately or prematurely assuming roles for which they are developmentally unready, so-called parentification. ${ }^{57}$ It is likely that the care-giving roles and responsibilities are increased in families where both mother and father suffer from chronic pain, and that girls are more likely than boys 
to take on care responsibilities in the home. ${ }^{58}$ Furthermore, young carers can, in some cases, feel a pressure to "be good" ${ }^{59}$ One might speculate that girls try to minimize the strain in the family by limiting their health risk behaviors, such as substance use. There is need for further studies to investigate different aspects of offspring's care-giving roles of and links to potential health risk behaviors, examining sex differences.

\section{Strengths and limitations}

To our knowledge, no studies have investigated substance use in the children of parents with chronic pain. One advantage of this study was its use of independent reports from both parents, which made it possible to examine the effect of maternal, paternal, and concurrent parental chronic pain. In addition, the current study had information on family composition, with specific information on whether the children lived with one or both biological parents. It is likely that our relatively strict definition of parental chronic pain, using clear case definitions that are sensitive to both the duration and severity of chronic pain, excluded less severe pain conditions. In addition, using data from a large population sample allowed us to control for the effects of pain due to a wide range of self-reported organ-specific illnesses and other important psychosocial factors. In logistic regression analyses with substance use as outcome, age was undoubtedly a potential confounder. However, there may be other confounders that we were not able to account for that could bias our findings.

Due to the cross-sectional nature of the presented data, we cannot determine any inference about causality between parental chronic pain and substance use in offspring. The combination of data from HUNT 3 (parents) and YoungHUNT 3 (adolescents) led to a substantial loss of respondents, which might have limited the internal and external validity of the study. Furthermore, it is possible that the exclusion of adolescents who had one or none participating parents in the HUNT 3 study might have led to an underestimation of the observed associations. Generally, people with poorer health are often underrepresented in population surveys. ${ }^{60}$ However, in the previous HUNT surveys, non-participation was only minimally dependent on health status, ${ }^{61}$ and associations between non-participation and chronic pain conditions were found to be weak. ${ }^{60}$ The results of our study were based solely on self-reports, which might have included both over-and under-estimates. However, recent studies have indicated that self-reports of chronic pain in adults ${ }^{62,63}$ and of substance use in adolescents ${ }^{40,64}$ have acceptable reliability.

\section{Clinical and scientific implications}

Targeted interventions offered to families of chronic pain sufferers could contribute to lowering the long-term suffering and costs of chronic pain. From a clinical perspective, it is especially important to evaluate the risk factors associated with adverse outcomes, such as substance use, especially when the adolescent offspring are exposed to concurrent maternal and paternal chronic pain. The present study demonstrates the importance of acknowledging the comorbid conditions of parents with chronic pain, as these factors influenced the association between parental pain and child outcomes. The association between parental chronic pain and substance use in the offspring may be bidirectional, as negative child behavior may exacerbate the parents' pain, mental distress, and diverse parenting. To identify causal pathways between parental chronic pain and health risk behavior in the offspring, longitudinal studies should be conducted. Future research should attempt to obtain more specific knowledge about personal, family and environmental factors in the children of parents with chronic pain.

\section{Conclusion}

We found higher odds for smoking and alcohol intoxication among boys whose parents both experienced chronic pain. Adjusting for parental smoking and parental symptoms of anxiety and depression attenuated the associations. Girls' level of substance use was not associated with parental chronic pain. The present study supplements the scarce body of evidence on substance use in children of parents with chronic pain.

\section{Acknowledgments}

The Nord-Trøndelag Health Study (the HUNT Study) is a collaboration among the HUNT Research Centre, the Faculty of Medicine, the Norwegian University of Science and Technology (NTNU), the Norwegian Institute of Public Health, and the Nord-Trøndelag County Council.

\section{Disclosure}

The authors report no conflicts of interest in this work.

\section{References}

1. Elliott AM, Smith BH, Penny KI, Smith WC, Chambers WA. The epidemiology of chronic pain in the community. Lancet. 1999;354(9186) 1248-1252.

2. Breivik H, Collett B, Ventafridda V, Cohen R, Gallacher D. Survey of chronic pain in Europe: prevalence, impact on daily life, and treatment. Eur J Pain. 2006;10(4):287-333. 
3. Evans S, de Souza L. Dealing with chronic pain: giving voice to the experiences of mothers with chronic pain and their children. Qual Health Res. 2008;18(4):489-500.

4. Hoftun GB, Romundstad PR, Rygg M. Association of parental chronic pain with chronic pain in the adolescent and young adult: family linkage data from the HUNT study. JAMA Pediatr. 2013;167(1):61-69.

5. Sherman AL, Bruehl S, Smith CA, Walker LS. Individual and additive effects of mothers' and fathers' chronic pain on health outcomes in young adults with a childhood history of functional abdominal pain. J Pediatr Psychol. 2013;38(4):365-375.

6. Grøholt EK, Stigum H, Nordhagen R, Köhler L. Recurrent pain in children, socio-economic factors and accumulation in families. Eur $J$ Epidemiol. 2003;18(10):965-975.

7. Coenders A, Chapman C, Hannaford P, et al. In search of risk factors for chronic pain in adolescents: a case-control study of childhood and parental associations. J Pain Res. 2014;7:175-183.

8. Kaasbøll J, Lydersen S, Indredavik MS. Psychological symptoms in children of parents with chronic pain - the HUNT study. Pain. 2012;153(5):1054-1062.

9. Evans S, Keenan TR, Shipton EA. Psychosocial adjustment and physical health of children living with maternal chronic pain. J Paediatr Child Health. 2007;43(4):262-270.

10. Roy R. Chronic Pain and Family: A Clinical Perspective. New York: Springer; 2006.

11. Dura JR, Beck SJ. A comparison of family functioning when mothers have chronic pain. Pain. 1988;35(1):79-89.

12. Bandura A. Self-efficacy: toward a unifying theory of behavioral change. Psychol Rev. 1977;84(2):191-215.

13. Compton WM, Volkow ND. Major increases in opioid analgesic abuse in the United States: concerns and strategies. Drug Alcohol Depend. 2006;81(2):103-107.

14. Patterson AL, Gritzner S, Resnick MP, Dobscha SK, Turk DC, Morasco BJ. Smoking cigarettes as a coping strategy for chronic pain is associated with greater pain intensity and poorer pain-related function. J Pain. 2012;13(3):285-292.

15. Knaster P, Karlsson H, Estlander AM, Kalso E. Psychiatric disorders as assessed with SCID in chronic pain patients: the anxiety disorders precede the onset of pain. Gen Hosp Psychiatry. 2012;34(1):46-52.

16. Sjøgren P, Ekholm O, Peuckmann V, Grønbæk M. Epidemiology of chronic pain in Denmark: an update. Eur J Pain. 2009;13(3):287-292.

17. Swendsen J, Conway KP, Degenhardt L, et al. Mental disorders as risk factors for substance use, abuse and dependence: results from the 10-year follow-up of the National Comorbidity Survey. Addiction. 2010;105(6):1117-1128.

18. Beman DS. Risk factors leading to adolescent substance abuse. Adolescence. 1995;30(117):201-208.

19. Barrett AE, Turner RJ. Family structure and substance use problems in adolescence and early adulthood: examining explanations for the relationship. Addiction. 2006;101(1):109-120.

20. Umberger W. Children of Parents With Chronic Noncancer Pain: A Comprehensive Review of the Literature. J Child Adolesc Psychiatr Nurs. 2014;27(1):26-34.

21. Kendler KS, Sundquist K, Ohlsson H, et al. Genetic and familial environmental influences on the risk for drug abuse: a national Swedish adoption study. Arch Gen Psychiatry. 2012;69(7):690-697.

22. Agrawal A, Lynskey MT. The genetic epidemiology of cannabis use, abuse and dependence. Addiction. 2006;101(6):801-812.

23. Hamilton AS, Lessov-Schlaggar CN, Cockburn MG, Unger JB, Cozen W, Mack TM. Gender differences in determinants of smoking initiation and persistence in California twins. Cancer Epidemiol Biomarkers Prev. 2006;15(6):1189-1197.

24. Korhonen T, Latvala A, Dick DM, et al. Genetic and environmental influences underlying externalizing behaviors, cigarette smoking and illicit drug use across adolescence. Behav Genet. 2012;42(4):614-625.

25. Saunders K, Von Korff M, LeResche L, Mancl L. Relationship of common pain conditions in mothers and children. Clin J Pain. 2007;23(3):204-213.
26. Evans S, Shipton EA, Keenan T. The relationship between maternal chronic pain and child adjustment: the role of parenting as a mediator. J Pain. 2006;7(4):236-243.

27. Silberg J, Rutter M, D’Onofrio B, Eaves L. Genetic and environmental risk factors in adolescent substance use. J Child Psychol Psychiatry. 2003;44(5):664-676.

28. Armstrong TD, Costello EJ. Community studies on adolescent substance use, abuse, or dependence and psychiatric comorbidity. J Consult Clin Psychol. 2002;70(6):1224-1239.

29. Strandheim A, Holmen T, Coombes L, Bentzen N. Alcohol intoxication and mental health among adolescents - a population review of 8983 young people, 13-19 years in North-Trøndelag, Norway: the YoungHUNT Study. Child Adolesc Psychiatry Ment Health. 2009;3(1):18.

30. Strandheim A, Bratberg G, Holmen T, Coombes L, Bentzen N. The influence of behavioural and health problems on alcohol and drug use in late adolescence - a follow up study of 2399 young Norwegians. Child Adolesc Psychiatry Ment Health. 2011;5(1):17.

31. Mäkelä P, Gmel G, Grittner U, et al. Drinking patterns and their gender differences in Europe. Alcohol Alcohol Suppl. 2006;41(1):i8-i18.

32. Pitel L, Geckova AM, vanDijk JP, Reijneveld SA. Degree of urbanization and gender differences in substance use among Slovak adolescents. Int J Public Health. 2011;56(6):645-651.

33. Strandheim A, Holmen TL, Coombes L, Bentzen N. Alcohol use and physical health in adolescence: a general population survey of 8,983 young people in North-Trøndelag, Norway (the Young-HUNT study). Subst Use Misuse. 2010;45(1-2):253-265.

34. Leino-Arjas P, Hänninen K, Puska P. Socioeconomic variation in back and joint pain in Finland. Eur J Epidemiol. 1998;14(1):79-87.

35. Patrick ME, Wightman P, Schoeni RF, Schulenberg JE. Socioeconomic status and substance use among young adults: a comparison across constructs and drugs. J Stud Alcohol Drugs. 2012;73(5):772-782.

36. Norwegian University of Science and Technology. The HUNT Study - a longitudinal population health study in Norway. Available from: http:// www.ntnu.edu/hunt. Accessed August 9,2014.

37. Norwegian University of Science and Technology. The Young-HUNT Study. Available from: http://www.ntnu.edu/hunt/young-hunt. Accessed August 9,2014.

38. Von Korff M, Jensen MP, Karoly P. Assessing global pain severity by self-report in clinical and health services research. Spine (Phila Pa 1976). 2000;25(24):3140-3151.

39. Jensen MK, Sjøgren P, Ekholm O, Rasmussen NK, Eriksen J. Identifying a long-term/chronic, non-cancer pain population using a one-dimensional verbal pain rating scale: an epidemiological study. Eur J Pain. 2004;8(2):145-152.

40. Lintonen T, Ahlström S, Metso L. The reliability of self-reported drinking in adolescence. Alcohol Alcohol. 2004;39(4):362-368.

41. Zigmond AS, Snaith RP. The Hospital Anxiety and Depression Scale. Acta Psychiatr Scand. 1983;67(6):361-370.

42. Bjelland I, Dahl AA, Haug TT, Neckelmann D. The validity of the Hospital Anxiety and Depression Scale: An updated literature review. J Psychosom Res. 2002;52(2):69-77.

43. Ewing JA. Detecting Alcoholism. The CAGE questionnaire. JAMA. 1984;252(14):1905-1907.

44. Skogen JC, Øverland S, Knudsen AK, Mykletun A. Concurrent validity of the CAGE questionnaire. The Nord-Trøndelag Health Study. Addict Behav. 2011;36(4):302-307.

45. O'Brien CP. The CAGE questionnaire for detection of alcoholism: a remarkably useful but simple tool. JAMA. 2008;300(17): 2054-2056.

46. Tambs K, Moum T. How well can a few questionnaire items indicate anxiety and depression? Acta Psychiatr Scand. 1993;87(5):364-367.

47. Peduzzi P, Concato J, Kemper E, Holford TR, Feinstein AR. A simulation study of the number of events per variable in logistic regression analysis. J Clin Epidemiol. 1996;49(12):1373-1379.

48. Vittinghoff E, McCulloch CE. Relaxing the rule of ten events per variable in logistic and Cox regression. Am J Epidemiol. 2007;165(6): 710-718. 
49. Carpenter JR, Kenward MG. Multiple Imputation and its Application. 1st ed. Chichester: John Wiley \& Sons; 2013.

50. van Buuren S. Flexible Imputation of Missing Data. Boca Raton, FL: Chapman and Hall/CRC Press; 2012.

51. Simons RL, Conger RD, Whitbeck LB. A multistage social learning model of the influences of family and peers upon adolescent substance abuse. Journal of Drug Issues. 1988;18(3):293-315.

52. Silver J, K. Chronic Pain and the Family: A New Guide. Cambridge: Harvard University Press; 2004.

53. Ardelt M, Day L. Parents, Siblings, and Peers: Close Social Relationships and Adolescent Deviance. J Early Adolesc. 2002;22(3):310-349.

54. Marmorstein NR, White H, Chung T, Hipwell A, Stouthamer-Loeber M, Loeber R. Associations between first use of substances and change in internalizing symptoms among girls: differences by symptom trajectory and substance use type. J Clin Child Adolesc Psychol. 2010;39(4): $545-558$.

55. Aldridge J, Becker S. Children as carers: the impact of parental illness and disability on children's caring roles. J Fam Ther. 1999;21(3): 303-320.

56. Strunin L, Boden LI. Family consequences of chronic back pain. Soc Sci Med. 2004;58(7):1385-1393.

57. Bekir P, McLellan T, Childress AR, Gariti P. Role reversals in families of substance misusers: a trans-generational phenomenon. Int J Addict. 1993;28(7):613-630.
58. Aldridge J. The experiences of children living with and caring for parents with mental illness. Child Abuse Review. 2006;15(2):79-88.

59. Cooklin A. Children as carers of parents with mental illness. Psychiatry. 2006;5(1):32-35.

60. Knudsen AK, Hotopf M, Skogen JC, Øverland S, Mykletun A. The health status of nonparticipants in a population-based health study: the Hordaland Health Study. Am J Epidemiol. 2010;172(11): $1306-1314$

61. Holmen J, Midthjell K, Krüger Ø, et al. The Nord-Trøndelag Health Study 1995-1997 (HUNT 2): Objectives, contents, methods and participation. Nor Epidemiol. 2003;13(1):19-32.

62. Dionne CE. Measuring chronic pain in populations. In: Croft P, Blyth FM, van der Windt D, editors. Chronic Pain Epidemiology: From Aetiology to Public Health. New York: Oxford University Press; 2010:45-61.

63. Landmark T, Romundstad P, Dale O, Borchgrevink PC, Kaasa S. Estimating the prevalence of chronic pain: validation of recall against longitudinal reporting (the HUNT pain study). Pain. 2012;153(7): 1368-1373.

64. Post A, Gilljam H, Rosendahl I, Meurling L, Bremberg S, Galanti MR. Validity of self reports in a cohort of Swedish adolescent smokers and smokeless tobacco (snus) users. Tob Control. 2005;14(2):114-117. 


\section{Supplementary material}

Table SI Numbers and percentages of missing data in the study

\begin{tabular}{llllll}
\hline Parental factors & \multicolumn{2}{c}{ Maternal } & & \multicolumn{2}{c}{ Paternal } \\
\cline { 2 - 3 } \cline { 6 - 7 } & $\mathbf{n}$ & $\%$ & & $\mathbf{n}$ & $\%$ \\
\hline Chronic pain & 154 & 4.6 & & 154 & 4.9 \\
Age & 7 & 0.2 & & 6 & 0.2 \\
Education & 12 & 0.4 & & 6 & 0.2 \\
Organ specific illness & 76 & 2.4 & & 93 & 2.9 \\
Symptoms of anxiety and & 588 & 18.2 & & 766 & 23.7 \\
depression (HADS) & & & & \\
Smoking & 328 & 10.2 & & 335 & 10.4 \\
Problematic alcohol use & 819 & 25.4 & & 898 & 27.8 \\
Child factors & Girls & & & Boys & \\
\hline Child age n=0 (0.0\%) & 0 & 0.0 & & 0 & 0.0 \\
Cohabitation (living with & 77 & 4.8 & & 87 & 5.3 \\
one/both parents) & & & & \\
Symptoms of anxiety and & 19 & 1.2 & & 48 & 2.9 \\
depression (SCL-5) & & & & \\
Smoking & 34 & 2.1 & & 54 & 3.3 \\
Alcohol intoxication & 238 & 14.9 & & 358 & 21.9 \\
Drug use & 30 & 0.9 & & 14 & 1.8 \\
\hline
\end{tabular}

Notes: Total sample $=3,227$ adolescents, $n=1,594$ girls, $n=1,633$ boys.

Abbreviations: HADS, Hospital Anxiety and Depression Scale; SCL-5, Hopkins Symptom Checklist.

Table S2 Parental education, organ disease, and smoking by chronic pain status

\begin{tabular}{|c|c|c|c|c|c|c|c|c|}
\hline & \multicolumn{4}{|c|}{ Mothers } & \multicolumn{4}{|c|}{ Fathers } \\
\hline & \multicolumn{2}{|c|}{$\begin{array}{l}\text { Chronic pain } \\
n=838\end{array}$} & \multicolumn{2}{|c|}{$\begin{array}{l}\text { No chronic pain } \\
n=2,230\end{array}$} & \multicolumn{2}{|c|}{$\begin{array}{l}\text { Chronic pain } \\
n=725\end{array}$} & \multicolumn{2}{|c|}{$\begin{array}{l}\text { No chronic pain } \\
n=2,245\end{array}$} \\
\hline & $\mathbf{n}$ & (\%) & $\mathbf{n}$ & $(\%)$ & $\mathbf{n}$ & (\%) & $\mathbf{n}$ & (\%) \\
\hline \multicolumn{9}{|l|}{ Education $^{\mathrm{a}}$} \\
\hline Compulsory & 138 & $(16.5)$ & 200 & $(9.0)$ & 126 & $(17.4)$ & 267 & $(\mathrm{I} I .4)$ \\
\hline Upper secondary & 436 & $(52.0)$ & 1,009 & $(45.4)$ & 453 & $(62.7)$ & $\mathrm{I}, 372$ & $(58.5)$ \\
\hline \multirow[t]{2}{*}{ Higher level (tertiary) } & 264 & $(31.5)$ & 1,014 & $(45.6)$ & 144 & $(19.9)$ & 705 & $(30.1)$ \\
\hline & 838 & $(100.0)$ & 2,223 & $(100.0)$ & 723 & $(100.0)$ & 2,344 & $(100.0)$ \\
\hline \multicolumn{9}{|l|}{ Organ disease $\mathrm{e}^{\mathrm{b}}$} \\
\hline None & 632 & $(76.6)$ & 1,896 & $(85.7)$ & 558 & $(78.2)$ & 1,965 & $(84.5)$ \\
\hline \multirow[t]{2}{*}{ One or more } & 193 & $(23.4)$ & 317 & $(14.3)$ & 156 & $(21.8)$ & 361 & $(15.5)$ \\
\hline & 825 & $(100.0)$ & 2,213 & $(100.0)$ & 714 & $(100.0)$ & 2,326 & $(100.0)$ \\
\hline \multicolumn{9}{|l|}{ Smoking } \\
\hline Non smoker & 320 & $(43.1)$ & 1,202 & $(59.0)$ & 300 & $(45.9)$ & 1,291 & $(60.3)$ \\
\hline Previous smoker & 181 & $(24.4)$ & 406 & (19.9) & 163 & $(25.0)$ & 425 & (19.8) \\
\hline \multirow[t]{2}{*}{ Current smoker } & 241 & (32.5) & 431 & $(21.1)$ & 190 & $(29.1)$ & 427 & $(19.9)$ \\
\hline & 742 & $(100.0)$ & 2,039 & $(100.0)$ & 653 & $(100.0)$ & 2,143 & $(100.0)$ \\
\hline
\end{tabular}

Notes: Numbers and percentages are based on original data (complete case). ${ }^{\mathrm{a} C}$ Compulsory ( $<10$ years), upper secondary ( $10-12$ years), and Higher level (tertiary) education ( $\geq 13$ years); ${ }^{b}$ Myocardial infarction, angina pectoris, other heart disease, stroke/brain hemorrhage, kidney disease, diabetes, cancer, epilepsy, chronic bronchitis, emphysema, asthma, or chronic obstructive pulmonary disease.

Journal of Pain Research

\section{Publish your work in this journal}

The Journal of Pain Research is an international, peer-reviewed, open access, online journal that welcomes laboratory and clinical findings in the fields of pain research and the prevention and management of pain. Original research, reviews, symposium reports, hypothesis formation and commentaries are all considered for publication.

\section{Dovepress}

The manuscript management system is completely online and includes a very quick and fair peer-review system, which is all easy to use. Visit http://www.dovepress.com/testimonials.php to read real quotes from published authors. 